\title{
Marie-Eve Thérenty, Mosaïques. Être écrivain entre presse et roman (1829-1836)
}

\section{Catherine Gaviglio-Faivre D'arcier}

\section{(2) OpenEdition}

1 Journals

\section{Édition électronique}

URL : http://journals.openedition.org/studifrancesi/30388

DOI : 10.4000/studifrancesi.30388

ISSN : 2421-5856

Éditeur

Rosenberg \& Sellier

\section{Édition imprimée}

Date de publication : 1 avril 2006

Pagination : 164

ISSN : 0039-2944

\section{Référence électronique}

Catherine Gaviglio-Faivre D'arcier, « Marie-Eve Thérenty, Mosaïques. Être écrivain entre presse et roman (1829-1836) », Studi Francesi [En ligne], 148 (XLX | I) | 2006, mis en ligne le 30 novembre 2015, consulté le 18 avril 2021. URL : http://journals.openedition.org/studifrancesi/30388 ; DOI : https://doi.org/ 10.4000/studifrancesi.30388

Ce document a été généré automatiquement le 18 avril 2021.

\section{(c) $(1) \odot$}

Studi Francesi è distribuita con Licenza Creative Commons Attribuzione - Non commerciale - Non opere derivate 4.0 Internazionale. 


\title{
Marie-Eve Thérenty, Mosaïques. Être écrivain entre presse et roman (1829-1836)
}

\author{
Catherine Gaviglio-Faivre D'arcier
}

\section{RÉFÉRENCE}

MARIE-EVE THÉRENTY, Mosaïques. Être écrivain entre presse et roman (1829-1836), Paris, Champion, 2003, pp. 735.

1 L'étude vaste et fouillée livrée par Marie-Eve Thérenty est novatrice à plus d'un titre. Elle s'inscrit dans un courant nouveau de l'histoire littéraire, qui, à la suite de R. Bellet et de P.Berthier, explore la question des rapports entre presse et littérature. Elle s'intéresse à une période qui gagne encore à être étudiée, comprise entre 1829 - date de création de la Revue de Paris qui offre une tribune reconnue et rémunératrice aux écrivains - et 1836, qui marque, avec la création du roman-feuilleton, l'avènement de «l'ère médiatique », pour reprendre le titre d'un autre ouvrage dont il a déjà été rendu compte dans ces colonnes.

2 M.-E. Thérenty formule une hypothèse de départ: l'écriture journalistique aurait contribué à la naissance de genres littéraires. Pour vérifier son hypothèse, l'auteur, après avoir décrit les contraintes du champ littéraire, s'attache à la lecture fine d'une masse considérable de textes en prose dus à des romanciers et parus dans des journaux ou des revues, qui servirent d'autant de laboratoires d'écriture. Ainsi peut être définie et mise en valeur une véritable poétique de la mosaïque. Le terme même de «mosaïque », emprunté au langage de l'époque, reflète bien la diversité des attitudes des écrivains face au journalisme en même temps qu'il rend compte de la multiplicité des écritures.

Le début de la Monarchie de Juillet voit en effet à la fois la défaillance de la librairie et l'importance croissante de la presse. Mais le champ journalistique est éclaté, fondé sur 
un modèle pyramidal. Il fascine par des possibilités d'écriture facile et alimentaire, mais demeure difficile d'accès et perçu comme peu valorisant d'un point de vue littéraire. Aussi toute la population des écrivains dits «minores ", au statut et à l'image problématique, soucieuse de vivre de sa plume en même temps que d'assumer une part de sacré, se lance-t-elle dans des stratégies littéraires relevant de la supercherie: biographies imaginaires, plagiat, utilisation de pseudonymes et de polyonymes, etc..., attitudes diverses qui témoignent d'une situation ambiguë et d'un désir d'autojustification et de mythification du réel.

Les auteurs de l'époque balancent entre deux formes d'écriture opposées, qu'ils utilisent souvent tour à tour, voire au sein d'une même œuvre. Si l'écriture « référentielle » des articles est la plus représentée durant la période étudiée, l'écriture «fictionnelle » finira par s'imposer avec le roman-feuilleton; mais son immixtion dans les autres genres pratiqués au sein d'un journal est déjà sensible. Qu'il s'agisse d'un article critique, d'une chronique, d'une étude de mœurs ou d'un récit de voyage, donc d'une écriture documentaire, les écrivains sont tentés d'y intégrer de la fiction. Au sein même de la fiction, il leur arrive par ailleurs de se livrer à de longues digressions, de nature «documentaire». Enfin, le journal favorisant des textes courts, les auteurs s'emballent pour la poétique du conte. Dans tous les cas, le savant dosage des deux formes d'écriture leur offre un compromis entre l'indépendance idéale du Poète et l'esclavage pesant du plumitif. Elle les conduit aussi progressivement à la création d'une nouvelle esthétique, celle de la mosaïque, à travers laquelle s'élabore le futur roman-feuilleton.

5 Plusieurs symptômes en sont révélateurs, en particulier l'apparition dans les textes de chronosèmes, indices d'actualités, et l'insertion de réalités historiques et géographiques. De plus, la permanence du discontinu et les jeux possibles sur les livraisons favorisent l'apparition de projets de fresques totalisantes, dont La Comédie humaine de Balzac constitue la forme la plus achevée. Mais Balzac n'était pas seul à nourrir une telle ambition. Frédéric Soulié rêvait d'une fresque historique, SamuelHenry Berthoud et Félix Davin de fresques provinciales, Léon Gozlan d'une fresque plutôt sociologique. Mais aucun ne parvint à créer une œuvre répondant au projet de départ, le résultat demeurant fragmenté et incomplet. Si seule la fresque balzacienne a échappé à l'oubli, c'est parce que son auteur sut jouer avec souplesse de toutes les dimensions de la mosaïque. Et, grâce à la circulation possible entre les différents textes, grâce au réinvestissement des personnages, son œuvre, à la façon d'un kaléidoscope, est en recomposition permanente et permet une lecture aventureuse.

6 En faisant revivre toute une population d'écrivains aujourd'hui oubliés - et minutieusement répertoriés à la fin de l'ouvrage, en parcourant toute la presse de l'époque - elle aussi répertoriée, M.-E. Thérenty illustre clairement son propos: la pratique journalistique a contribué à l'évolution de l'écriture romanesque autour de 1830 et ce doublement. On y voit d'abord les auteurs cheminer difficilement vers une position qui les amènera à lier indissolublement leur personne à un nom, réel ou de plume. Surtout, l'esthétique de la mosaïque, mise en valeur dans la production de l'époque, rend compte d'une pratique discontinue de l'écriture, à laquelle deux sousgenres au moins semblent redevables: le roman-feuilleton dans un premier temps, le roman réaliste ensuite. 
7 Au terme de cette belle étude, l'auteur ouvre une piste nouvelle de recherche: l'émergence du roman mosaïque constitue-t-elle une traduction de l'échec douloureux de l'Histoire, ressenti en 1830 ? 